Differencing the Diffusion Equation on Unstructured Heahes in 2-D

\title{
Todd S Palner
}

October 24, 1994

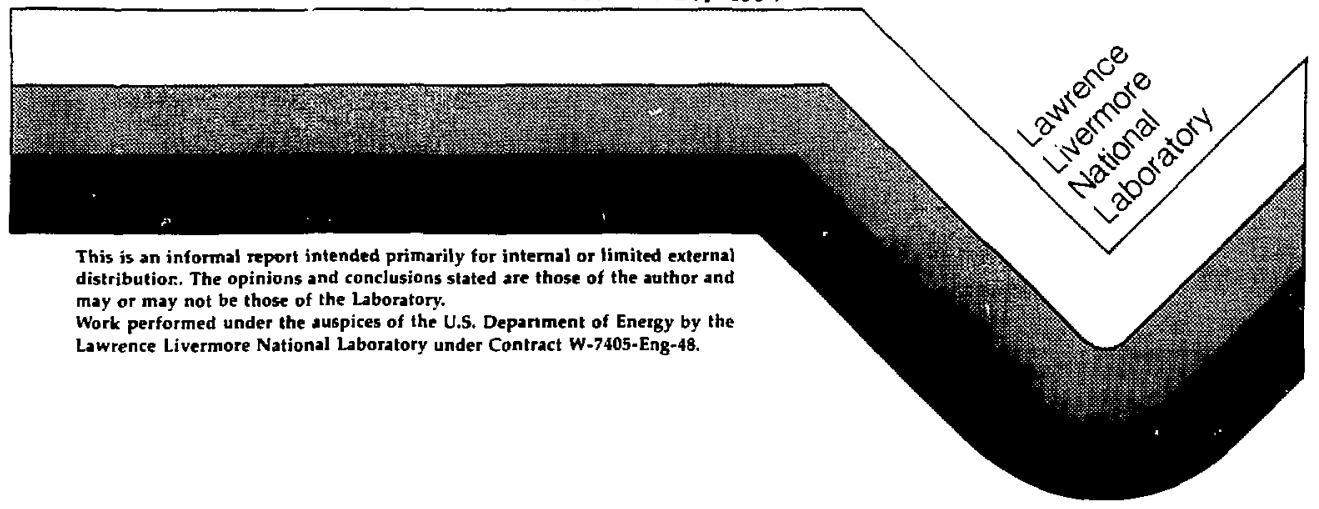




\section{DISCLAIMIR}

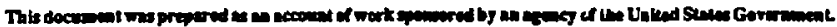

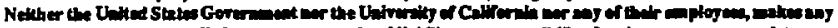

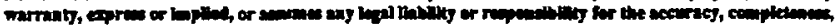

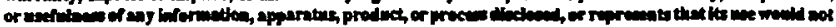

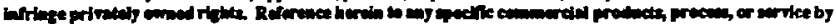

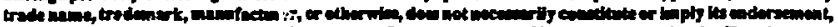

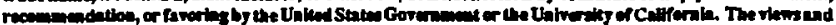

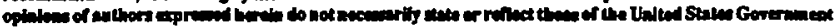

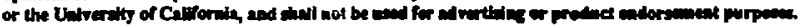

This report has been repredeced diructly from the but anllable cops.

Available to DOE and DOE contractors fires the Once of Scientinc apd Techules] Intormethe

P.O. Bax 62, Onk RIdze, TTa 37031

Prices avalable foud (615) 576-401, FTS 6264401

Aviliable to the publle frome the

National Techeical tolormution Service

U.S. Departineat of Commeres 5225 Port Rojel Rt,

Springrold, VA 22161 


\title{
Differencing the Diffusion Equation on Unstructured Meshes in 2-D
}

\author{
Todd S. Palmer \\ Lawrence livermore National Laboratory \\ Ijivermorc, California 94550
}

\section{INTRODUCTION}

During the last few years, there has been an increased effort to devise robust transport differencings for unstruetured meshes, specifically arbitrarily connected grids of polygons. Adams ${ }^{1,2,3}$ has investigated unstructured mesh discrelization locliniques for the even- and odd-parity forms of the tramsport equation, and for the more traditional first-order form. Conversely; development of unstructured mesh diffusion methods has becn lacking. While Morel $^{4}$, Kershaw ${ }^{5}$, Shestakn ${ }^{6}$ and others have done a great deal of work on diffusion schemes for logically-rectangular grids, to our knowledge there has becn no work on discretizations of the diftusion cquation ori unstructured meshes of polygons.

In this paper, we introfuse a point-eentered diffusion differencing for two-dimensional unstructured meshes. Wr have designed the rnethod to have the following altractive proparties: !' the scheme is equivalent to the standard five-point poirtl-centered scheme on an orthogonal mesh; 2) the method prescrves the homogeneoms linear solution; 3) the method gives second-order accurace; 1) we haw: st ricl conservation within the control volume surrounding cach poim: and i) the mumerical solution converges to the exact result as the mesh

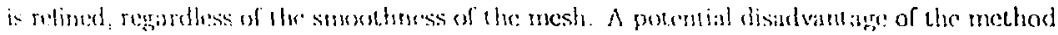

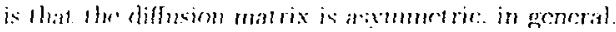

\section{D):III:ATH(N)}

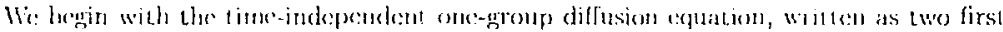
arder soultitions:

$$
\begin{gathered}
\ddot{\nabla} \cdot j+a_{n} \sigma=Q \\
f(1) \Gamma i
\end{gathered}
$$

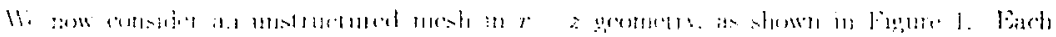

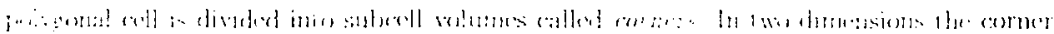

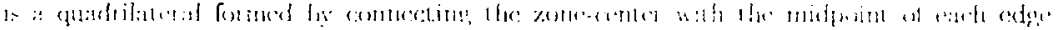

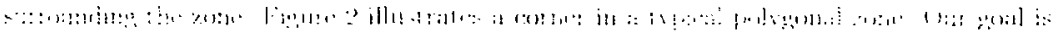

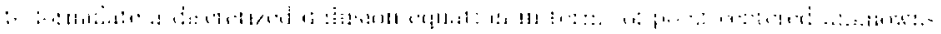

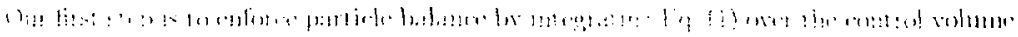

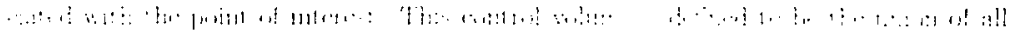




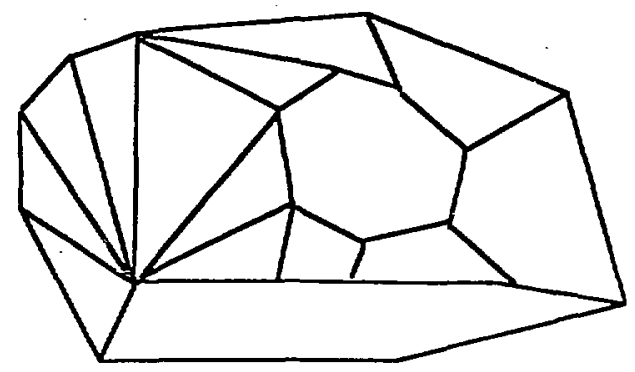

Figure 1: A Porlion of an Unstruclured Mcsh.

corners surrounding the spexificed point. Arter performing this integration, we obtain

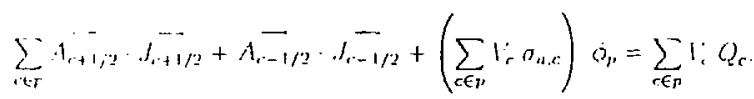

Referring agrain to Figure $2, V_{r}$ is the volume of corner $c_{;}, A_{r-1 / 2}$ and $A_{r+1 / 2}$ are the areas of

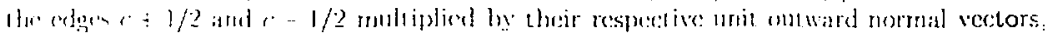
(O) is L refors to all the comers a which surroumb the point $p$.

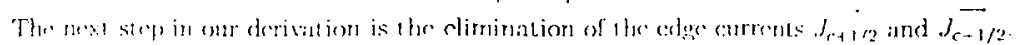

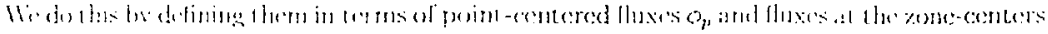

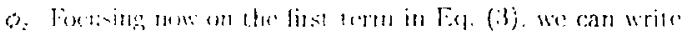

$$
\begin{aligned}
A_{c+1 / 2} \cdot J_{1+1 / 2} & =-1)_{r} A_{c+1 / 2}(\vec{n} \cdot \vec{\nabla} 0) \mid \\
& =-D_{1} A_{c+1 / 2}(\vec{n} \cdot \because 0)_{1}
\end{aligned}
$$

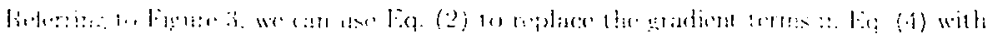

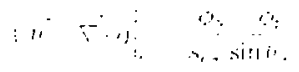

$$
\begin{aligned}
& \because 11 \quad \because \cdots, \quad \therefore \quad .4 \%
\end{aligned}
$$




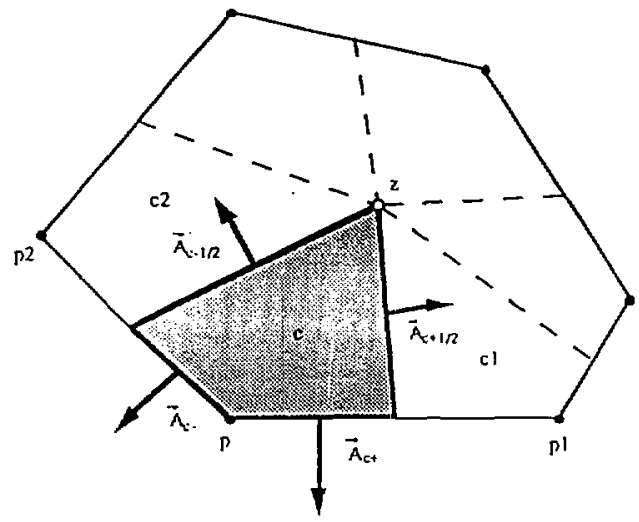

Figure: 2: A Corner and its Bounding Surfacos.

Simple lincar interpolations and extrapolations allow us to write,

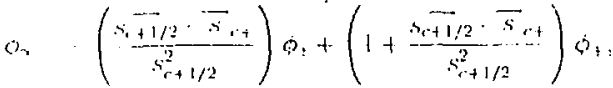

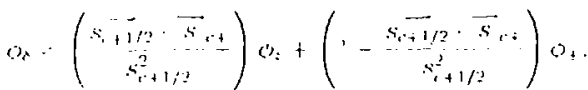

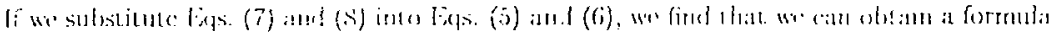
fir bit of the [orm

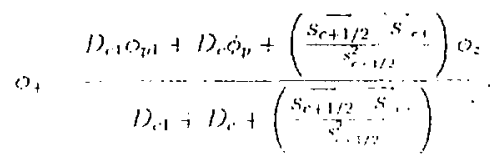

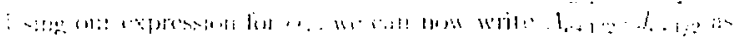

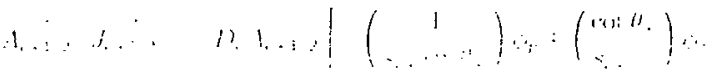

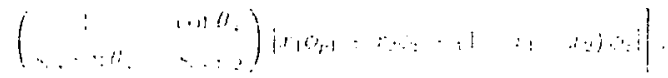




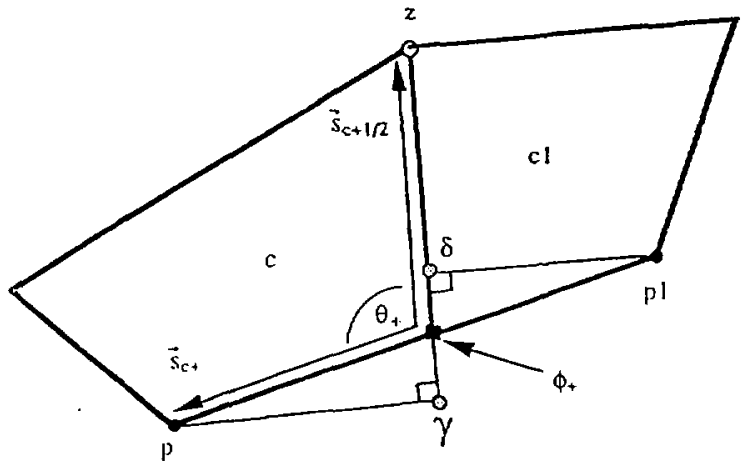

Figure 3: The: gradicoll calconation for $\widehat{\Lambda_{c+1 / 2}} \cdot \overrightarrow{J_{c+1 / 2}}$.

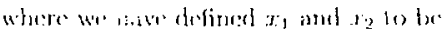

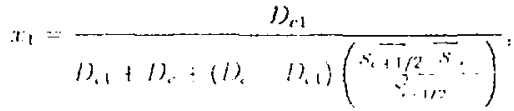

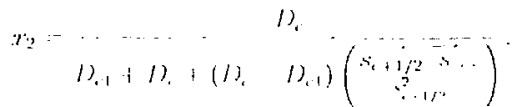

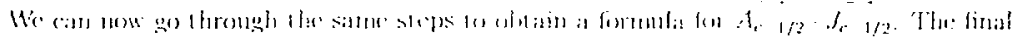
result, reforing lo Figrare: 1 is

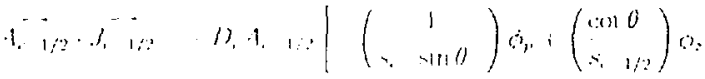

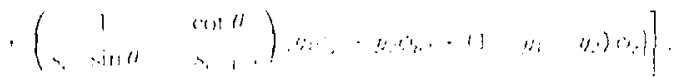

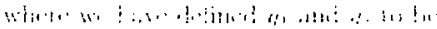

$$
\text { ' } i
$$

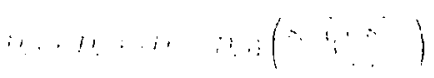




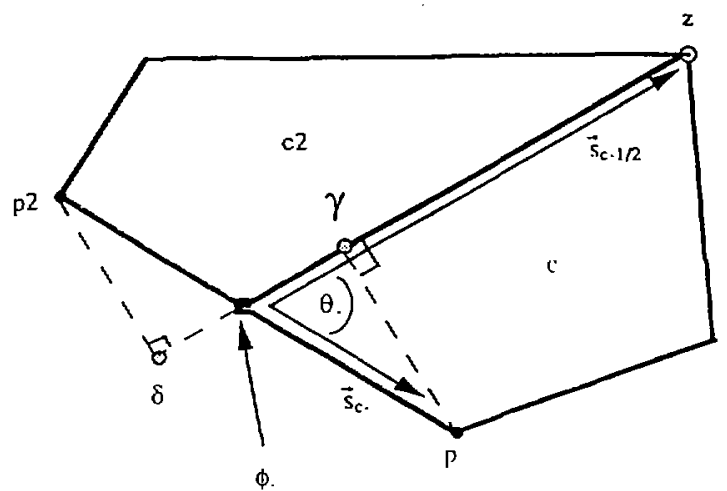

Figure 1: The gradient calculation for $\widehat{A} \overline{s-1 / 2} \cdot \overrightarrow{J_{e-1 / 2}}$

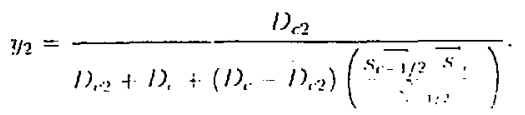

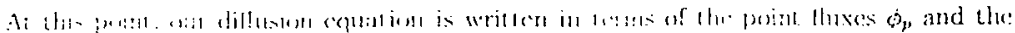

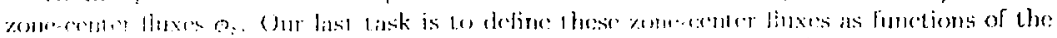

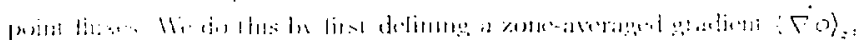

$$
\begin{aligned}
& \langle\nabla \theta) \quad \quad \quad \int_{2} d_{2}, i \\
& \frac{1}{d} f_{2} d s \vec{a}
\end{aligned}
$$

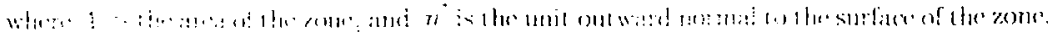

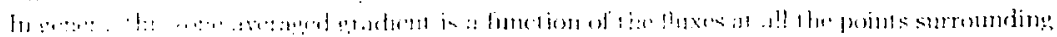

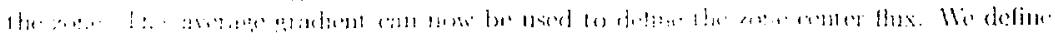

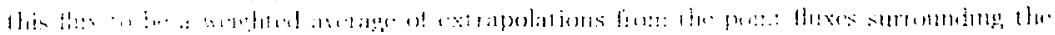
*ats!.

$$
\therefore \because \cdots \quad \therefore \quad \therefore \quad \therefore \quad \text { a }
$$


We define the weights $w_{p}$ to be inverse length weights,

$$
w_{p}=\frac{1}{s_{p \rightarrow z}},
$$

where $s_{p-x}$ is the distance from the point $p$ to the rone-center $z$. This allows us to eliminate the cell center hux in terms of the point fluxcs. Morcl's cell-center method, which has many of the same altractive characteristics as our method, is forced to retain two kinds of unknowns (cell-enter and esll-eds: Ruxes). while: we have only anc kind (point Ruxes).

This completely defines our mstructured dilfusion method, aside from boundary con-

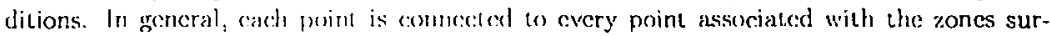
rounding that point. On all orlingronal mesh, the connectivity reduces to the standard point-centered five-point stromil.

\section{NIIMFIRICAI, RESUITS}

In this section, we present 1.Jur resulls of a few lest problems designed to demonstrate that. our method preserves the lintar solution ard is second-order accurate. First we consider the following test problem in a unit cylinder:

$$
\begin{aligned}
& -\frac{i}{\partial_{z}} \nu \frac{\partial \dot{j}}{\partial z}=0 \\
& \phi\left(r_{1} \mathrm{l}+2 D\right)=1 \text {, }
\end{aligned}
$$

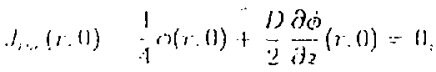

$$
\begin{aligned}
& f(0.2)-f(1,2)-0
\end{aligned}
$$

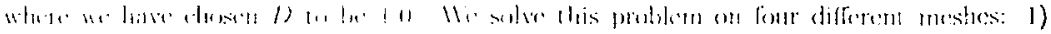

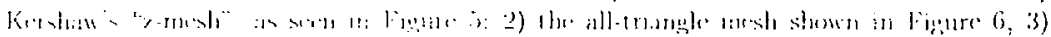

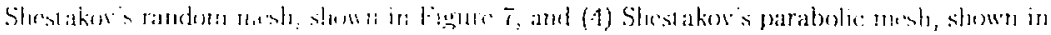

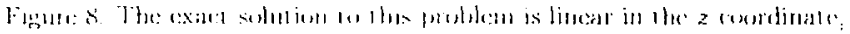

$$
o(r+\cdots)=\frac{z+2 I)}{1+11)}
$$

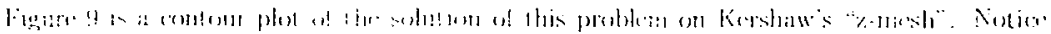

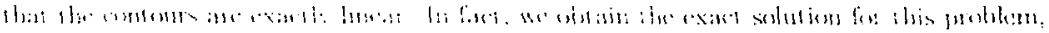

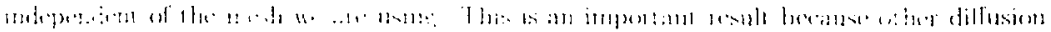

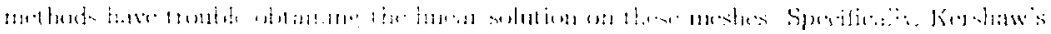

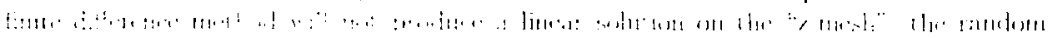

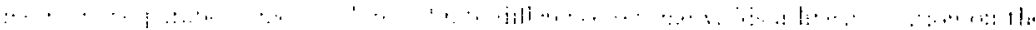

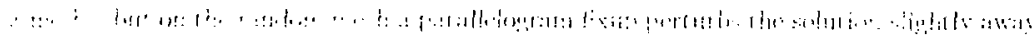
$\therefore \quad \cdots:$ : 


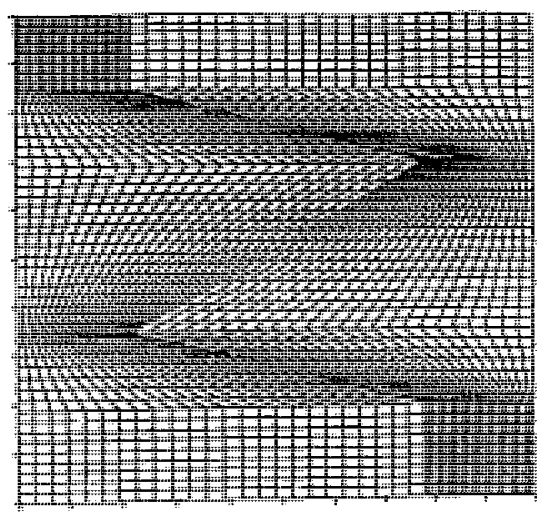

Figure is: Kershaw's "\%-rrceth".

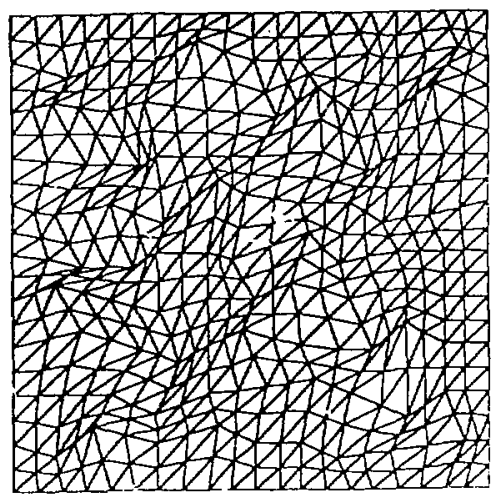

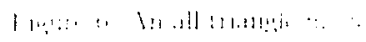




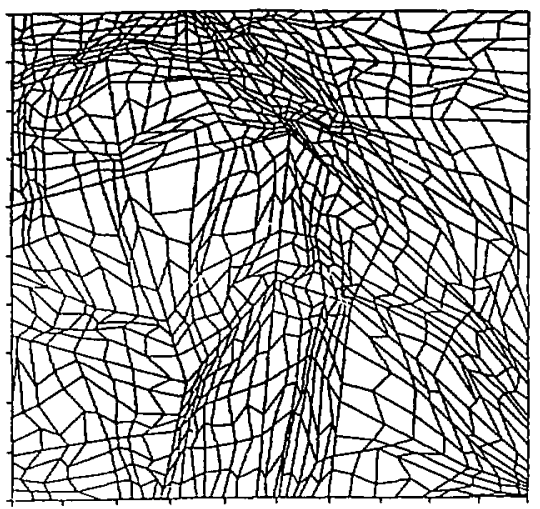

Figurer 7: Shestakcov's random mesh.

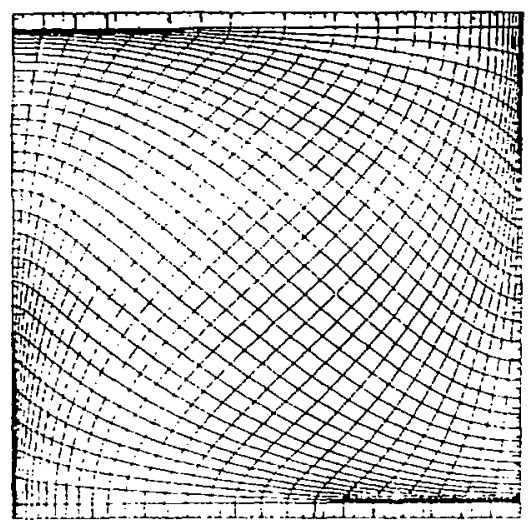




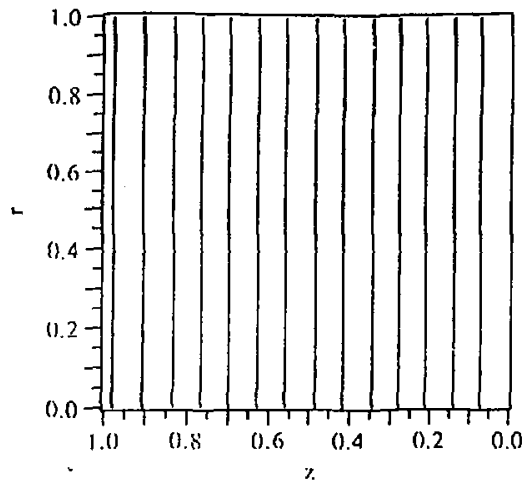

Figure 9: Comlensts of the solution to Kershaw"s "\%-mesh" problem.

A second lest problom, designed to ilhustrate that this methed is second-order accuratc, involves the solution of the following dilfusion problem:

$$
\begin{aligned}
& \text { i) } 1) \frac{\partial \dot{\theta}}{i)_{z}}-z^{2} \text {. } \\
& \therefore(r .1+21))-1 \text {. } \\
& \therefore \quad 2(1)-0 \text {. } \\
& J(11, \quad j(1 . z)=0
\end{aligned}
$$

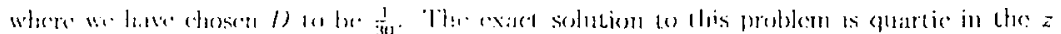
coordinatr.

$$
\left.\partial(r: 2)=\frac{1}{121)} \dot{\dot{1}}\left(\frac{1+81)}{1+11)}\right)(z+21)-z^{4}\right)
$$

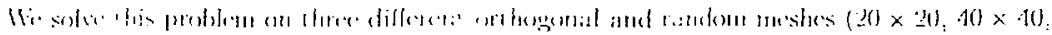

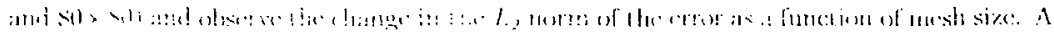

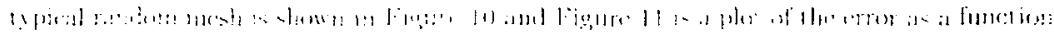

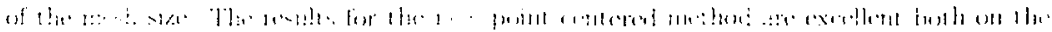

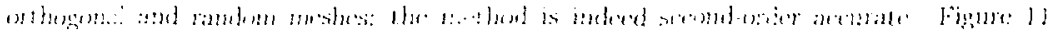

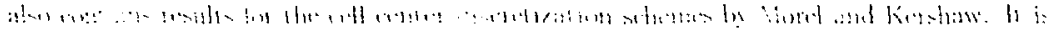

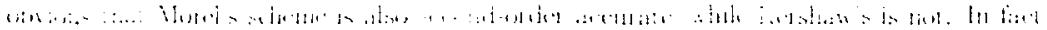

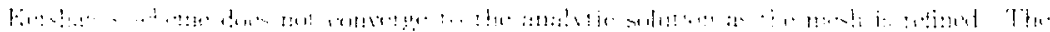

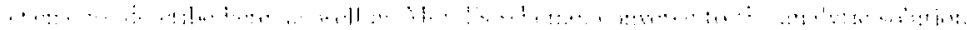




\section{CONCLUSIONS}

We have been successful in derivirg and implementing a diffusion discretization for unstructured meshes in 2-D which has many attractive properties. However there are two issues which must be considered and quantified: 1) the overhead involved in calculating the matrix on an unstructured mesh, and 2) the expense in the iterative solution of the asymmetric matrix. There is no question that navigating on an unstructured mesh costs more than on an orthogonal mesh (cither in storage or CPU time). Nlso, depending on the structure of our dillusion matrix, its solution can lake significantly longer to oblain. These concerns are being addressed, but are not resolved at this tirne.

\section{ACKNOWLEDGMENTS}

The author would like to thank Marvin Adams and Donald Burton Cor their comments and suggestions.

\section{REFERRENCES}

1. M.1. Adams: "N Now Transporl Discreti\%ation Scheme for Arbitrary Spatial Meshes in XY Geometry:" Proc. ANS Topical Mecting: Advances in Mathemalics, Computations, and IRcactor Physics, $\Lambda$ pril 29-May 2, 1991, Piltsburgh, PA, Vol. 3, Sec. 13.2, pp 2-] through 2.9 (1991).

2. T.S. Palmer: "Cumilinear Geomcty. Transport Diseretimations in Thick. Diflusive Re-

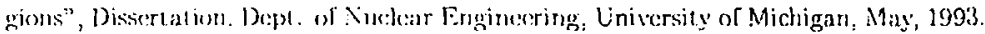

3. M.I. Mdams. "Discontimous Finte--Fitement. Transport Solutions in the Thick Diffusion

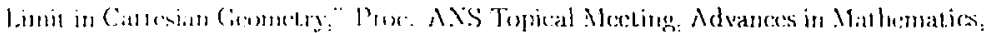

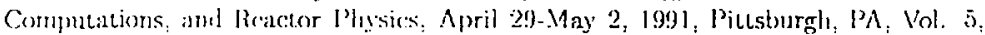
Scc. 21.1, pp 3-1 thronght 3-15 (1991).

4. J.E. Morel, J.E. Dendy, Jr., Michael I. Hall and Stephen W. White, "A Cell-Centered Lagrangian-Mesh Dillusion Difforoncing Schcine," J. Comp. Phys., 103, 286 (1992).

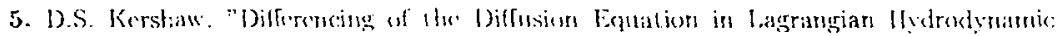

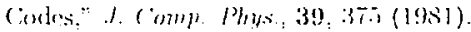

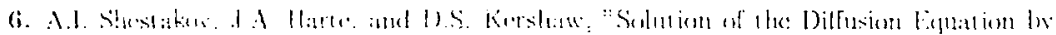

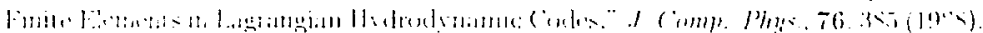

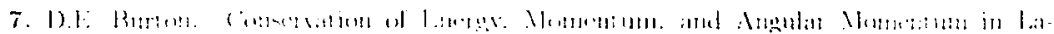

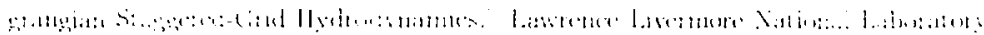

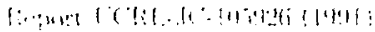

